\title{
Primordial magma ocean outgassing on Earth and Mars recorded in D/H
}

\author{
K. PAHLEVAN ${ }^{1 *}$,L. SCHAEFER ${ }^{2}$, M. M. HIRSCHMANN ${ }^{3}$ \\ ${ }^{1}$ Carl Sagan Center, SETI Institute, Mountain View, CA, \\ USA, *kaveh.pahlevan@seti.org \\ ${ }^{2}$ Dept. of Geological Sciences, Stanford, Stanford, CA, USA \\ ${ }^{3}$ Dept. of Earth Sciences., U. Minnesota, Minneapolis, MN, \\ USA
}

Core-mantle-atmosphere differentiation on the Earth and Mars was facilitated by formation of magma oceans [e.g., 1]. Whereas mantle siderophile abundances are used to infer the conditions $\left(\mathrm{P}, \mathrm{T}, \mathrm{x}_{\mathrm{i}}\right)$ for metal-silicate equilibration [e.g., 2], no equivalent proxies for magma ocean-atmosphere equilibration have been identified. Conditions of magma ocean-atmosphere last equilibration determine the chemical composition of the earliest atmosphere. In particular, over the range of oxygen fugacity $\left(\mathrm{fO}_{2}\right)$ that can characterize a magma ocean surface $(\approx \mathrm{IW}-2$ to $\approx \mathrm{QFM})$, the composition of co-existing atmosphere ranges from reducing $\left(\mathrm{H}_{2}-\mathrm{CO}\right.$-rich) to oxidizing $\left(\mathrm{H}_{2} \mathrm{O}-\mathrm{CO}_{2}-\right.$ rich) [3], with consequences for the earliest geologic history.

Motivated by these questions, we have developed a model of primordial atmosphere evolution to track the history and fate of volatiles outgassed from a magma ocean [4]. By coupling atmospheric physics with isotope geochemistry, we propose new links between the chemical compositon of the outgassed atmosphere and the hydrogen isotope composition of the hydrosphere, now constrained by ancient samples from the Earth and Mars [5,6]. We find that D/H enrichment in a surface hydrosphere is a reflection of the $\mathrm{H}_{2} / \mathrm{H}_{2} \mathrm{O}$ outgassed into the earliest atmosphere, and an oxybarometer for magma ocean equilibration. For Earth, chondritic D/H of early oceans point towards minimal D-enrichment and an oxidizing $\left(\mathrm{H}_{2} \mathrm{O}-\right.$ $\mathrm{CO}_{2}$-rich) outgassed Hadean atmosphere [4], consistent with inferences from zircons [7]. By contrast, the $\approx 2-3 x \mathrm{D} / \mathrm{H}$ enrichment inferred for early Mars' hydrosphere $[6,8]$ points towards reducing $\left(\mathrm{H}_{2}\right.$-CO-rich) outgassing from the Martian magma ocean, as also expected from experimental petrology of low-P ( $<20 \mathrm{GPa})$ core formation [9]. The consequences for magma ocean processes and the initial conditions for geologic evolution on Earth and Mars will be disucssed.

References: [1] Elkins-Tanton, L. (2008) EPSL, 271, 181191. [2] Wood, B.J., et al. (2006) Nature, 441, 825-833. [3] Hirschmann, M.M., EPSL, (2012) 341-344, 48-57. [4] Pahlevan, K. et al., (2019), EPSL, 526, 115770. [5] Pope, E. et al. (2012) PNAS, 109, 4371-4376. [6] Mahaffy, P., et al. (2015) Science, 347, 412-414. [7] Trail, D. et al. (2011), Nature, 480, 79-82. [8] Usui, T. et al, (2015), EPSL, 410, 140-151. [9] Armstrong, K. et al. (2019) Science, 365, 903-6. 